\title{
Reflexões acerca da educação especial e da educação do campo numa perspectiva inclusiva
}

\author{
Reflections about the special education and the education \\ of the countryside in an inclusive perspective
}

\author{
Rodrigo Simão Camacho ${ }^{1}$ \\ Jaqueline Machado Vieira ${ }^{2}$
}

\section{Resumo}

Este artigo tem o objetivo de fazer uma reflexão acerca da inclusão escolar tendo como destaque a Educação Especial e a Educação do Campo. Como metodologia foi utilizado um levantamento bibliográfico presente em livros, artigos de periódicos, teses e dissertações e uma análise documental acerca da Lei Brasileira de Inclusão da Pessoa com Deficiência (Estatuto da Pessoa com Deficiência) e o Manual de Operações do Programa Nacional de Educação na Reforma Agrária (PRONERA). A inclusão deve promover a interação e acolher a todos, sem exceção, no sistema escolar, com a garantia de equidade de acesso, sejam eles educandos do campo ou cidade, com deficiências ou sem deficiências, para que possam alcançar a cidadania com o direito do respeito à diversidade. A realidade para os povos do campo tem sido sempre de uma educação que não ultrapassa os anos iniciais do ensino fundamental, por isso, há ainda um grande número de analfabetos no campo. O PRONERA é um exemplo importante de Educação do Campo na esfera da política pública. Seu principal objetivo é fortalecer o meio rural enquanto território de vida em todas as suas dimensões: econômicas, sociais, políticas, culturais e éticas. Orientase por cinco princípios fundamentais: a inclusão, a participação, a interatividade, a multiplicação e a parceria.

Palavras-chave: Inclusão Escolar. Educação do Campo. Educação Especial. PRONERA.

\section{Abstract}

The purpose of this article is to reflect on school inclusion, focusing on Special Education and Education of the Countryside. As a methodology, a bibliographic

\footnotetext{
${ }^{1}$ Doutor em Geografia pelo Programa de Pós-Graduação em Geografia (PPGG) da Universidade Estadual Paulista (Unesp/Presidente Prudente). Docente do curso de Licenciatura em Educação do Campo (LEDUC) na Faculdade Intercultural Indígena (FAIND) da Universidade Federal da Grande Dourados (UFGD). Docente nos Programas de Pós-Graduação em Geografia da UFGD e na Universidade Federal de Mato Grosso do Sul (UFMS/Três Lagoas). E-mail: rogeo@ymail.com.

${ }^{2}$ Licenciada e Bacharela em Geografia (FCT-UNESP). Mestra em Educação (FAED-UFGD). E-mail: jakquet@hotmail.com.
} 
survey was used in books, periodicals, theses and dissertations and a documentary analysis on the Brazilian Law on the Inclusion of Persons with Disabilities (Statute of the Person with Disabilities) and the Operations Manual of the National Education Program in Agrarian Reform (PRONERA). Inclusion should promote interaction and welcome all, without exception, into the school system, with the guarantee of equal access, be they rural or urban educators, with disabilities or without disabilities, so that they can achieve citizenship with the right of the respect to diversity. The reality for the rural people has always been an education that does not exceed the initial years of elementary school, so there are still a large number of illiterates in the field. The PRONERA is an important example of Education of the Countryside in the sphere of public policy. Its main objective is to strengthen the rural environment as a territory of life in all its dimensions: economic, social, political, cultural and ethical. It is guided by five fundamental principles: inclusion, participation, interactivity, multiplication and partnership.

Key words: School Inclusion. Education of the Countryside. Special Education. PRONERA.

\section{Introdução}

Este artigo tem o objetivo de fazer uma discussão acerca da inclusão escolar tendo como destaque a Educação Especial e a Educação do Campo. A metodologia utilizada foi a pesquisa bibliográfica em livros, artigos de periódicos, teses e dissertações a respeito da Educação Inclusiva e da Educação do Campo. Na parte documental, em específico, analisamos a Lei Brasileira de Inclusão da Pessoa com Deficiência (Estatuto da Pessoa com Deficiência), o Manual de Operações do Programa Nacional de Educação na Reforma Agrária (PRONERA) e a Segunda Pesquisa Nacional de Educação na Reforma Agrária (II PNERA).

O movimento na perspectiva da educação inclusiva é amplo e não se direciona apenas as pessoas com deficiência (Educação Especial), seja ela motora, cognitiva e sensorial, mas compreende ao envolvimento de todos educandos que vivem segregados do seu acesso a educação formal ou que se encontram desrespeitados nos seus direitos garantidos em relação as suas especificidades sociais, culturais, étnicas, raciais, territoriais etc. e, que portanto, tem o direito de ter conteúdos e metodologias condizentes com a sua condição social. 
A inclusão deve promover a interação e acolher a todos, sem exceção, no sistema escolar, com a garantia de equidade de acesso, bem como de conteúdos e metodologias que respeitem a especificidade dos educandos, sejam eles do campo ou cidade, com deficiências ou sem deficiências, para que possam alcançar a autonomia e a cidadania com o direito do respeito à diversidade. No seu sentido mais amplo, visa o desenvolvimento dos processos que garanta aos estudantes vulneráveis, excluídos e os com deficiência uma educação emancipatória e de qualidade dentro das escolas regulares.

Dentre as propostas de educação na perspectiva da inclusão social, temos a Educação do Campo. Sua origem se dá devido à exclusão social e educacional, na qual, foram submetidas, historicamente, as populações do campo. Esta realidade está relacionada com a questão agrária no Brasil baseada na concentração fundiária e na expulsão dos povos indígenas de seus territórios tradicionais e das populações camponesas de sua terra de trabalho. A educação sempre foi inacessivel para estas populações excluídas que não ultrapassavam, em sua maioria, as séries iniciais do ensino fundamental, por isso, há ainda um grande número de analfabetos no campo (CAMACHO, 2016).

O Programa Nacional de Educação na Reforma Agrária (PRONERA) é a politica pública mais importante de Educação do Campo no Brasil. Foi criado em 1998 a partir da demanda dos movimentos socioterritoriais e sindicais camponeses. É uma experiência inovadora porque foi implementado em um território historicamente marcado pela ausência de políticas públicas educacionais. Seu objetivo é fortalecer o campo como território de vida em todas as suas dimensões: ambiental, econômica, social, política, cultural e ético. É constituído por meio de uma parceria entre universidades, movimentos sociais e governo federal, representado pelo Instituto Nacional de Colonização e Reforma Agrária (INCRA). É um programa baseado numa gestão tripartite. Demonstrando um avanço na gestão democrática das políticas públicas no país. Seus projetos se orientam por cinco princípios fundamentais: a inclusão, a participação, a interatividade, a multiplicação e a 
parceria. (BRASIL, 2011; CAMACHO, 2014, 2016, 2017a, 2018; CAMACHO et al., 2015).

\section{Reflexões Sobre os Processos de Inclusão Escolar de Educandos Com ou Sem Deficiência do Campo ou da Cidade}

A educação inclusiva é um conceito amplo e não diz respeito apenas as pessoas com deficiência, mas compreende ao conjunto de todos educandos que vivem segregados pelo sistema capitalista e excludente no nosso país que nega o direito de acesso à educação formal ou nega o direito de garantia de conteúdos e metodologias para as especificidades dos educandos. Os conceitos de inclusão vêm ganhando destaque no discurso educativo, tendo contribuído para tal os princípios e orientações preconizados nas declarações oficiais de diversos organismos internacionais e nacionais apontando para significativas mudanças na forma de equacionar o papel e a função da escola na sociedade atual (MADUREIRA; NUNES, 2015).

\footnotetext{
No contexto da educação, o termo inclusão admite, atualmente, significados diversos. Para quem não deseja mudança, ele equivale ao que já existe. Para aqueles que desejam mais, ele significa reorganização fundamental do sistema de educacional. Enfim, sob a bandeira da inclusão estão práticas e pressupostos bastante distintos, o que garante um consenso apenas aparente e acomoda diferentes posições que, na prática, são extremamente divergentes. (MENDES, 2006, p. 70).
}

Consideramos que a inclusão deva promover a interação e acolher todos, sem exceção, no sistema escolar. Ressaltamos a necessidade da garantia de equidade de acesso de todos educandos, campo e cidade, com deficiências ou sem deficiências, no sistema escolar para que possam alcançar a autonomia e a cidadania com o direito do respeito à diversidade. Conforme afirma a autora Mantoan (2005, p. 96).

Inclusão é a nossa capacidade de entender e receber o outro e, assim, ter o privilégio de conviver e compartilhar com pessoas diferentes de nós. A educação inclusiva acolhe todas as pessoas, sem exceção. É para o estudante com deficiência física, para os que têm comportamento mental, para os superdotados, e para toda criança 
que é discriminada por qualquer outro motivo. Costumo dizer que estar junto é se aglomerar no cinema, no ônibus e até na sala de aula com pessoas que não conhecemos. Já inclusão é estar com, é interagir com outro.

Para a autora Bruno (2006) ao falar de inclusão, entende que o cerne está na interação entre as pessoas com respeito a diversidade sociocultural e a garantia de apoio e acolhimento para aquelas que têm necessidades especiais. É o verdadeiro sentido de "Educação para todos".

\begin{abstract}
A inclusão está fundada na dimensão humana e sociocultural que procura enfatizar formas de interação positivas, possibilidades, apoio às dificuldades e acolhimento das necessidades dessas pessoas, tendo como ponto de partida a escuta dos alunos, pais e comunidade escolar. Essas duas dimensões fazem nosso olhar convergir para o interior da escola, fazendo então surgir a necessidade de se compreender quais seriam as reais dificuldades que os alunos com necessidades educacionais especiais encontram na classe comum. $\mathrm{O}$ que significa realmente educação para todos? Em que implicaria, na realidade, a igualdade de oportunidades? Quais as demandas e necessidades que emergem no processo de aprendizagem? Como a escola tem se organizado para responder a essas demandas e necessidades? Como se dá a prática pedagógica para a diversidade? Qual é o nivel de participação dos alunos, pais e comunidade na elaboração do projeto político pedagógico e na tomada de decisões? (BRUNO, 2006 p. 11).
\end{abstract}

Nesse sentido, procuramos refletir sobre os processos de inclusão com base no conceito de alguns autores que nos aponta que é a partir do convívio cotidiano dentro dos espaços escolares do campo ou da cidade que encontramos através dos diálogos com a comunidade escolar respostas aos seus problemas concretos. Algumas reflexões feitas pela autora Bruno (2006): "Como a escola tem se organizado para responder a essas demandas e necessidades?" perpassam a análise das relações concretas estabelecidas em sala de aula e o processo de ensino-aprendizagem desses educandos, mas cabe não somente ao professor mediar e resolver essas questões, pois é dever do Estado garantir a acessibilidade ao ensino formal para todos.

Neste texto, não vamos conseguir respostas que resolvam a totalidade das questões relacionadas à inclusão, porém iremos dar alguns apontamentos para as possibilidades que norteiam os caminhos que entendemos que levam a superação de alguns problemas. Segundo Bruno (2013, p.303), a inclusão no espaço escolar requer mudanças na sua forma de organização em, pelo 
menos, três aspectos, que se conduzam pelo principio da colaboração e interação entre pais, professores, profissionais da educação especial e próprios educandos.

A proposta de educação inclusiva propõe três formas interdependentes de ação organizacional da escola: a formação de rede de apoio com a participação de profissionais da educação especial, pais e equipe de atendimento terapêutico, quando necessário para avaliação e planejamento; articulação e trabalho conjunto do professor do ensino regular e educação especial; aprendizagem cooperativa, criação de uma atmosfera de aprendizagem em sala de aula em que alunos com vários interesses e habilidades diferentes trabalham em conjunto. [...].

Na esfera dos avanços nas políticas públicas, destacamos o Estatuto da Pessoa com Deficiência (2015). O referido Estatuto foi atualizado em julho de 2015 e institui o conhecimento da Lei n. 13.146/2015 - Lei Brasileira de Inclusão da Pessoa com Deficiência (Estatuto da Pessoa com Deficiência) que prevê em seu Art. $1^{\circ}$ :

Art. $1^{\circ}$ É instituída a Lei Brasileira de Inclusão da Pessoa com Deficiência (Estatuto da Pessoa com Deficiência), destinada a assegurar e a promover, em condições de igualdade, o exercício dos direitos e das liberdades fundamentais por pessoa com deficiência, visando à sua inclusão social e cidadania. Parágrafo único. Esta Lei tem como base a Convenção sobre os Direitos das Pessoas com Deficiência e seu Protocolo Facultativo, ratificados pelo Congresso Nacional por meio do Decreto Legislativo no 186, de 9 de julho de 2008, em conformidade com o procedimento previsto no § 3o do art. 5o da Constituição da República Federativa do Brasil, em vigor para o Brasil, no plano jurídico externo, desde 31 de agosto de 2008, e promulgados pelo Decreto no 6.949, de 25 de agosto de 2009, data de início de sua vigência no plano interno.

Diante do exposto da Lei instituída em (2015), levamos em consideração que na implementação dessa politica é preciso refletir sobre as condições de acesso e permanência das pessoas com deficiência nas escolas do campo e da cidade, considerando que além de reforçar suas especificidades, seja pessoal ou local, devemos quebrar barreiras e propor medidas inovadoras para a escola, para que os mesmos sejam inclusos. Por isso, a luta dos movimentos sociais pela perspectiva da inclusão é a busca constante pelo acesso e permanência desses educandos. Vejamos o que considera a Declaração de Salamanca (UNESCO, 1994) sobre esse processo nas escolas. 
[...] considera-se que é na escola regular que todas as crianças e jovens devem ser educadas, independentemente das suas condições físicas, intelectuais, sociais, emocionais, linguísticas ou outra; por sua vez, as diferenças individuais são perspectivadas não como algo negativo que é necessário combater, mas sim como um valor de referência, já que fundamentam e justificam mudanças na gestão do currículo das escolas e, consequentemente, no processo de ensino e aprendizagem. Preconiza-se, em última análise, uma escola e uma pedagogia centrada no aluno, tornando-se assim imprescindivel a implementação de processos de formação inicial e contínua de professores que assegurem o desenvolvimento de práticas educativas inclusivas. Nesta ordem de ideias, uma vez que se pretende garantir a todos o acesso a uma educação de qualidade e assegurar a plena participação e integração na sociedade considera-se que, a escola em geral e a sala de aula em particular, constituem ambientes prioritários para o desenvolvimento de uma Educação Inclusiva (UNESCO, 2001), combatendo-se deste modo a exclusão e a marginalização social. [...]. (MADUREIRA; NUNES, 2015, p.04).

A Declaração de Salamanca vem dar suporte de acessibilidade aos educandos com deficiência aos espaços escolares, mas a mesma não garante, que de fato, os educandos possam ser incluídos em sala de aula regular, pois, para além disso, vivemos em uma sociedade organizada nos pressupostos do sistema capitalista que produz a exclusão e a segregação das pessoas com e sem deficiência, além de manter os educadores com intensas cargas de trabalho nos espaços escolares dificultando o seu amadurecimento teórico e a aquisição de novas práticas pedagógicas. Nesse sentido, reforçamos a necessidade de construir com a sociedade os valores da perspectiva inclusiva. $\mathrm{Na}$ educação formal, precisamos inovar e pensar numa escola que se reestruture e se distancie dos debates ligados apenas ao fracasso escolar dos educandos, é preciso fazer diferente e dar respostas e essas novas práticas pedagógicas, inovando, qualificando e potencializando as práticas.

Para colaborar com nosso debate, os estudos dos autores Ainscow et al. (2006) e Echeita (2013) apontam que há seis formas possiveis de equacionar os conceitos que colaboram com essa perspectiva inclusiva, sendo assim, há diferentes conceitos que de forma interdependente levam a construção da inclusão como um todo. Os autores comparam com um poliedro de múltiplas facetas, sendo que cada parte contém uma essência que não esgota o significado total do conceito em si. Vejamos a figura a seguir que norteia a ideia dos autores: 
Figura 1 - Seis Formas de Perspectivar a Inclusão.

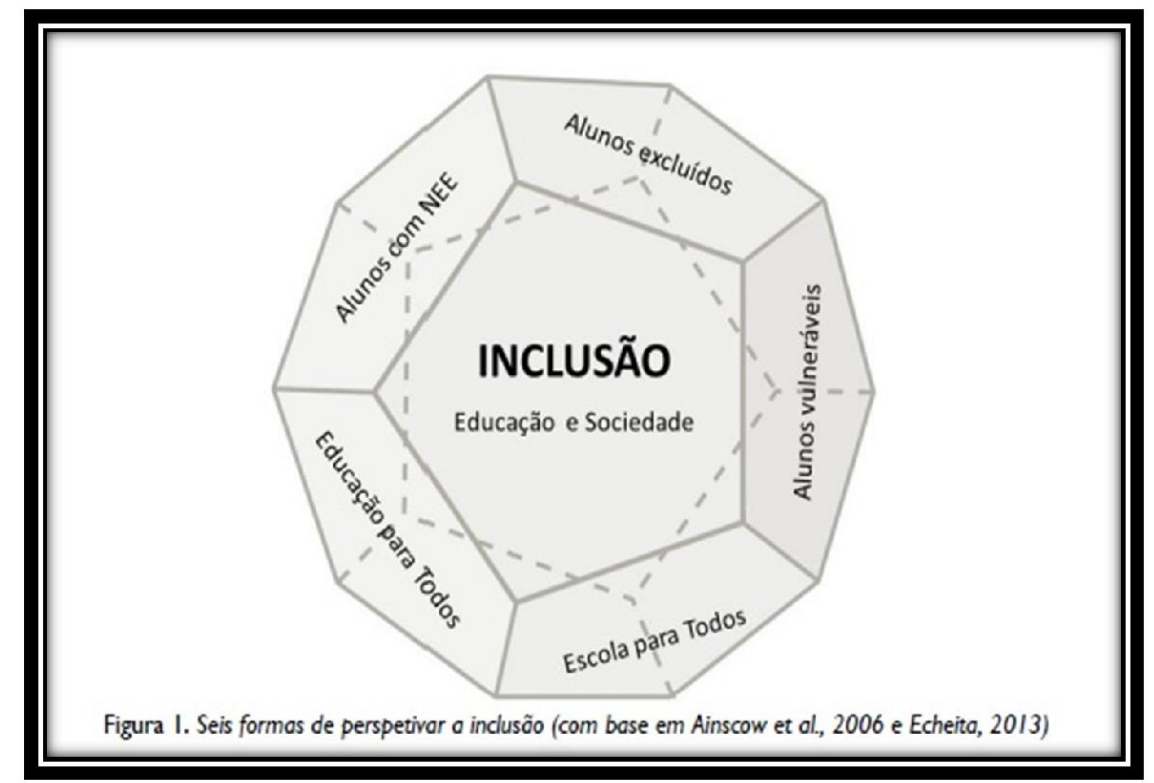

Fonte: Ainscow et al. (2006) e Echeita (2013) apud Madureira e Nunes (2015).

Partindo dessa figura que permeia a ideia de inclusão dos autores, os mesmos nos ajudam a compreender que o conceito de inclusão é uma meta para atender a sociedade num todo, mas também, pode ser, mais específico, um princípio fundamental que busque uma intervenção educativa e pedagógica. No seu sentido mais amplo, visa o desenvolvimento dos processos que garanta aos estudantes vulneráveis, excluídos e os com deficiência (ilustrados como NEE na figura), uma educação emancipatória e de qualidade dentro das escolas regulares (MADUREIRA; NUNES, 2015).

Para a efetivação da inclusão, não nos basta a reflexão teórica sobre o atual cenário escolar segregador no qual vivemos, é preciso vivenciar esses espaços, ouvir os professores que, muitas vezes, são silenciados. É necessário dialogar com pais, gestão escolar, monitores e todo corpo da escola. Precisamos construir diálogos críticos e construtivos com professores e estudantes dentro das escolas do campo e da cidade, assim teremos educandos pensantes, criadores e críticos de seus próprios conhecimentos no cotidiano escolar (VIEIRA, 2018). 
Segundo Pierre Bourdieu (1998), temos uma educação pautada em valores oriundos do sistema capitalista, cuja preocupação é a transmissão de conhecimentos que reproduzem as estruturas dominantes do poder políticoeconômico ao invés da crítica e a reflexão. Neste cenário, educandos e educadores são ambos, sujeitos oprimidos, e a educação é parte de uma sociedade capitalista mecanizadora e reprodutivista do modelo hegemônico, negando o direito dos estudantes a criticidade e a criação dos conhecimentos que parta da realidade vivida por eles, tendo em vista que há uma desvalorização do capital cultural ${ }^{3}$ que os educandos possuem antes de chegar à escola.

A inclusão escolar está diretamente ligada à inserção de novas ideias. O processo educacional inclusivo exige mudanças e rompimentos com características excludentes existentes nas escolas e propõe uma nova estrutura, reconhecendo e valorizando a diversidade (cor, raça, gênero) como condição humana. Neste caso, devemos dar destaque nas potencialidades das pessoas com ou sem deficiência em sala de aula e na identificação de suas possibilidades em aprender, pois só assim construiremos condições favoráveis para o processo inclusivo, acessivel, permanente e não excludente da diversidade dos sujeitos (PRIETRO, 2008).

A sociedade necessita refletir sobre este tema a fim de colocar em prática os modelos educacionais inclusivos permanentes. Mas, para isto, é preciso salientar que não temos na realidade uma formação profissional adequada para a maioria dos educadores, por isso, precisamos avançar para potencializar esse debate a fim de gerar modificações, realmente significativas nos ambientes escolares. Os educadores, não podem se alienarem do processo de construção de adaptação para um novo modelo que visa incluir de fato as pessoas com deficiência, mas, para isto, é preciso debater quais são essas formas metodológicas mais eficazes para potencializa-las e torna-las de fato

\footnotetext{
${ }^{3} \mathrm{Na}$ sociedade capitalista a cultura das classes subalternas é desvalorizada e a cultura das classes dominantes tende a ser imposta para toda a sociedade. Por isso, para autor, a palavra capital não serve apenas para denominar o capital econômico, visto que o acesso diferenciado aos bens sociais, assim como no caso da diferenciação de acesso ao capital econômico, também acarreta uma diferenciação na hierarquia social, auxiliando na reprodução das estruturas dominantes vigentes (CAMACHO, 2014).
} 
acessiveis e permanentes, caso contrário, corremos o risco da contradição, segregando e excluindo ainda mais os estudantes com deficiência, dentro da própria perspectiva inclusiva que aqui defendemos.

Assim, ressaltamos que apenas a presença física do educando na escola do campo ou da cidade, não quer dizer que, de fato, ele esteja incluído, ou seja, esse ambiente tem que estar totalmente acessivel, além de que os professores devem possuir formação adequada e especializada, com metodologias de ensino, de qualidade, com modelos de interação e que atendam os educandos com deficiência e que possam assim, além de auxiliálos, mais do que isso, possam educá-los de forma objetiva e satisfatória e que os torne permanente nesse sistema, para com seu mundo vivido.

A instituição escolar se depara com sujeitos reais com suas diferenças, suas marcas de identidades individuais e coletivas diferentes, por isso, afirmar essas marcas do diferente como negativas, acarreta demarcar a efetiva exclusão. É possivel construir processos pedagógicos específicos com esses educandos para que atinjam patamares de competências diferentes. É fundamental se pensar na adequação de práticas diferentes de estudos e unificar os sujeitos envolvidos no processo educativo em sua totalidade: pais, educando com ou sem deficiência e educadores. Dessa forma, se faz necessário uma formação contínua com educadores críticos, atualizados e muito envolvidos, buscando a sua autonomia e incentivando-os a se tornarem reflexivos e investigadores de sua própria prática educacional (SCHLUNZEN, 2014).

Concluímos nossa reflexão afirmando que é necessário, urgentemente, dialogar com os princípios voltados a sociedade na perspectiva inclusiva. É preciso pensar num espaço escolar organizado com respeito às diferenças. Para incluir sem segregar é necessário pensar um espaço acessivel e que ofereça demandas políticas, sociais e econômicas (tecnológicas) para que assim a escola não seja seletiva, excludente e conservadora, onde só se aceita um modelo padrão de aluno considerado como "ideal". Portanto, ressaltamos a importância e a necessidade de projetos pedagógicos educacionais críticos que atendam a nova realidade enfrentada nas escolas e de práticas 
metodológicas e avaliativas que forneçam mecanismos que visem não somente o acesso, mas também, a permanência de todos educandos e educadores. Dessa maneira, fica evidente que essa perspectiva deve perpassar a análise acerca dos espaços inclusivos das escolas permitindo o diálogo, a interação e inovação entre educadores, educandos e familiares e toda sociedade brasileira, é o conjunto do trabalho e envolvimento de todos esses sujeitos que garantirá um processo eficaz e vivo nesses (des)caminhos da perspectiva inclusiva.

\title{
A Gênese da Educação do Campo no Brasil: Combate a Marginalização Social e Educacional
}

\author{
Eu quero uma escola do campo \\ onde o saber não seja limitado \\ que a gente possa ver o todo \\ e possa compreender os lados \\ eu quero uma escola do campo \\ onde esteja o ciclo da nossa semeia \\ que seja como a nossa casa \\ que não seja como a casa alheia \\ (Gilvan dos Santos).
}

A criação de um novo projeto de Educação do Campo está relacionada com os esforços conjuntos de algumas entidades que formaram a Articulação Nacional em 1998, em favor da Educação Básica no Campo. As entidades que promoveram este movimento foram: a Conferência Nacional dos Bispos do Brasil (CNBB), o Movimento dos Trabalhadores Sem Terra (MST), Fundo das Nações Unidas para a Infância (UNICEF), Organização das Nações Unidas para a Educação, a Ciência e a Cultura (UNESCO), da Universidade de Brasília (UNB) e o Grupo de Trabalho da Reforma Agrária (GTRA). A primeira conferência chamada "Por uma Educação Básica do Campo" ocorreu em Luziânia - GO, em 1998. Foi o marco inicial para transformar este paradigma educacional em politica pública (CALDART, 2005; CAMACHO et al., 2015; CAMACHO, 2017b, 2018). 
As instituições participantes denunciam o descaso histórico do governo brasileiro para com a escola pública do campo no Brasil. Por isso, a luta pela Educação do Campo tem sua gênese na superação da exclusão histórica na qual foram submetidas às populações do campo. A educação sempre foi inacessivel para estas populações excluídas. Predominou no campo uma educação que não ultrapassa as séries iniciais do ensino fundamental. Isto se comprova no fato de que há ainda um grande número de analfabetos no campo. (CAMACHO et al., 2015).

Uma pesquisa por amostragem realizada pelo Instituto Nacional de Colonização e Reforma Agrária (INCRA), em 2010, revelou que o acesso à educação continua sendo um grande desafio para populações rurais estabelecidas em todas as regiões do país. No que diz respeito aos dados sobre o ensino superior no Brasil, a região Norte tem 390.752 famílias assentadas, e menos de 1\% com ensino superior concluído. A região Nordeste tem 302.513 famílias assentadas, mas menos de 1\% tem diploma universitário. A região Centro-Oeste tem 138.000 famílias assentadas, destes, 1\% possuem nível superior, e 1,33\% estão estudando. A região Sudeste tem 40.156 famílias assentadas, destes, 1,01\% tem curso superior concluído, e 1,16\% estão estudando. A região Sul tem 34.991 famílias assentadas: menos de 1\% com diploma universitário, e 1,09\% estão estudando (BRASIL, 2011).

Apesar de estudos e dados do censo mostrar uma expansão quantitativa no acesso escolar, as desigualdades sociais e regionais, bem como os niveis de analfabetismo, ainda são altos, especialmente, nas regiões Norte e Nordeste (PAIVA, 2004). Uma das principais causas destes números negativos é a inexistência de escolas próximas às residências das pessoas, a falta de transporte escolar, ou devido às condições de vida precárias de suas famílias exigem que eles comecem a trabalhar ou ajudar nas tarefas domésticas em uma idade muito precoce. A ausência de políticas públicas demonstra o tratamento desigual e discriminatório recebido pela população rural. Esta atitude negligente por parte do Estado tem levado a problemas educacionais de longa data, como o analfabetismo; crianças, adolescentes e jovens fora da escola ou sem escola; discrepâncias entre idade e série, 
repetição e fracasso; conteúdo inapropriado; problemas com a titulação, salários e carreiras dos professores; e uma oferta de escola que é geralmente reduzida para as quatro primeiras séries do ensino fundamental (ARROYO, 2013).

O movimento "Por uma Educação do Campo" foi criado para fazer frente a esta realidade de abandono por parte do Estado. Este movimento começou a exigir politicas públicas de instituições governamentais, bem como o financiamento para a investigação relacionada com questões educacionais em comunidades rurais. O silêncio, esquecimento, e até mesmo a falta de interesse em comunidades rurais em pesquisas sociais e educacionais é um ponto que estava se tornando preocupante. O movimento de Educação do Campo foi criado para relatar esse silêncio e o esquecimento das instituições governamentais, instituições de investigação de financiamento, programas de pós-graduação e estudiosos que estudam as questões sociais e educacionais (ARROYO, 2004).

Apesar de a educação ser reconhecida como um direito humano desde os anos 1980 e que a promoção de uma educação de alta qualidade é o segundo dentre os oito objetivos para o desenvolvimento no milênio para uma sociedade mais justa e sustentável (PNUD, 2014), este reconhecimento não atingiu áreas rurais brasileiras. Moradores de comunidades rurais foram totalmente excluídos desta conquista; este direito só manteve-se no nível abstrato do conceito de cidadania e não atendeu as necessidades específicas e concretas da realidade das comunidades rurais (ARROYO, 2004; CAMACHO et al., 2015). Portanto, a Educação do Campo é uma condição fundamental para que a população rural possa exercer sua cidadania (FERNANDES; MOLINA, 2004).

Em suma, a marginalização social e educacional vivida pelos moradores das comunidades rurais, devido à falta de políticas públicas voltadas para a sua realidade, engendrou a emergência de lutas de sujeitos coletivos que reagiram diante dessas situações sociais. Dentre estas lutas, destaca-se: a luta pela terra e pela reforma agrária que desencadeou a luta pela Educação do Campo (CAMACHO et al., 2015). 


\title{
PRONERA: Política Pública de Inclusão, Participação, Interatividade, Multiplicação e Parceria na Educação do Campo
}

\begin{abstract}
Nos assentamentos da Reforma Agrária espalhados por todo o Brasil vivem hoje mais de 500 mil famílias que demandam a efetivação do direito constitucional a uma educação básica que atenda a suas necessidades para alavancar o desenvolvimento socioeconômico e cultural das comunidades de modo sustentável. Promover a alfabetização e elevar o nivel de escolaridade desse segmento populacional, por meio de ações educativas articuladas entre si, foi o desafio a que se propôs a Pronera, uma politica pública singular, incluída na agenda governamental por pressão da sociedade civil. (ANDRADE; DI PIERRO, 2004, p. 33).
\end{abstract}

A politica pública de Educação do Campo não teve sua origem no Estado, mas sim, nos movimentos sociais do campo. Estes já haviam construído experiências de educação popular do campo. O Estado, por meio do Ministério da Educação (MEC), apenas abriu um espaço para as vozes dos sujeitos que reivindicavam uma politica pública de Educação do Campo. Reivindicavam a obrigação do Estado em garantir o direito de todos à educação pública. A busca da conquista de uma escola pública de qualidade como "direito de todos e dever do Estado" é a sintese dos objetivos de uma política pública de educação (MUNARIM, 2006).

De acordo com o Manual de Operações do PRONERA, o Programa Nacional de Educação na Reforma Agrária é uma política pública de Educação do Campo desenvolvida nas áreas de Reforma Agrária. Seu principal objetivo é fortalecer o meio rural enquanto território de vida em todas as suas dimensões: econômicas, sociais, políticas, culturais e éticas. O Programa nasceu em 1998 da luta das representações dos movimentos sociais e sindicais do campo (BRASIL, 2011) com o objetivo de proporcionar educação aos jovens e adultos moradores dos assentamentos de Reforma Agrária. No entanto, apesar de ter iniciado suas atividades com a educação de jovens e adultos, já em 1999 ampliou suas modalidades educativas para os cursos técnicos/profissionalizantes e os de ensino superior, sendo que atualmente 
conta, também, com pós-graduação. O PRONERA compreende hoje as ações de alfabetização de jovens e adultos, escolarização nos níveis fundamental, médio, superior e pós-graduação, formação continuada de professores, formação técnico-profissional para a saúde, a comunicação, a produção agropecuária e a gestão do empreendimento rural. Todas estas modalidades de educação estão pautadas em metodologias de ensino adequadas a realidade sociocultural do campo (ANDRADE; DI PIERRO, 2004).

No período de 1998 a 2010, o PRONERA foi responsável pela escolarização e formação de cerca 400 mil jovens e adultos assentados e/ou acampados da reforma agrária. O Programa capacitou cerca de 300 profissionais egressos dos cursos de ciências agrárias para atuarem na Assessoria Técnica, Social e Ambiental junto aos Projetos de Assentamento de Reforma Agrária e agricultura familiar (BRASIL, 2011). Para a atualização dos dados, o PRONERA lançou a Segunda Pesquisa Nacional de Educação na Reforma Agrária (II PNERA). Esta foi uma pesquisa realizada em parceria com o Instituto Nacional de Estudos e Pesquisa Anísio Teixeira (MEC-INEP) e o Instituto de Pesquisas Aplicadas (IPEA). A pesquisa teve como objetivo caracterizar a demanda educacional e diagnosticar a situação do ensino ofertado nos assentamentos da Reforma Agrária. O resultado da pesquisa é que no período entre 1998 a 2011 foram realizados 320 cursos do PRONERA por meio de 82 instituições de ensino em todo o país, sendo 167 de Educação de Jovens e Adultos Fundamental, 99 de nível Médio e 54 de nível Superior. Os cursos foram realizados em 880 municípios, em todas as unidades da federação (BRASIL, 2015).

Em termos de politica pública específica, por meio da interação com os movimentos sociais camponeses, a experiência do PRONERA conseguiu se relacionar com a extrema diversidade de situações presentes no campo brasileiro. Diversidade esta que envolve desde a heterogeneidade dos sujeitos sociais do campo, bem como a diversidade das condições culturais, ambientais, geográficas e de organização da produção agrícola. Esta característica do PRONERA somente foi possivel devido à interlocução direta que foi travada com os protagonistas deste processo (MOLINA, 2004). 
De acordo com Márcia Regina Andrade e Maria Clara Di Pierro (2004b), o PRONERA, enquanto política pública, é uma experiência inovadora na medida em que foi implantada num território marcado historicamente pela exclusão social e ausência de políticas públicas na área da educação. Sua inovação se dá a partir de duas características que lhes são inerentes. A primeira é a de criar e implementar uma metodologia de ensino relacionada à realidade sociocultural dos assentamentos. A segunda característica inovadora é a de se constituir sob um modelo de gestão participativa envolvendo três parcerias fundamentais: universidades, movimentos sociais $e$ governo federal. Esta parceria entre universidades, movimentos sociais e governo federal (Superintendências Regionais do INCRA) é um modelo de gestão tripartite. O grau de democracia na gestão compartilhada depende das características dos parceiros, isto é, do envolvimento e da forma de participação de cada sujeito (JESUS, 2004). As universidades cumprem as seguintes funções: fazer a mediação entre os movimentos sociais e o Instituto Nacional de Colonização e Reforma Agrária (INCRA), fazer a gestão administrativo-financeira e a coordenação pedagógica dos projetos. Os movimentos sociais estão representados, principalmente, pelo MST, pelos sindicatos filiados a Confederação Nacional dos Trabalhadores da Agricultura (Contag) e pela Comissão Pastoral da Terra (CPT). Eles fazem a ligação direta com a comunidade. O INCRA é responsável pelo acompanhamento financeiro, logístico e pela articulação interinstitucional (ANDRADE; DI PIERRO, 2004a).

O processo para a aprovação dos projetos é feito da seguinte maneira, as instituições de ensino encaminham o projeto para a Superintendência Regional do INCRA, onde a equipe do PRONERA o avaliará. Depois, o projeto é encaminhado à Coordenação-Geral de Educação do Campo e Cidadania para análise da Comissão Pedagógica Nacional (CPN) (BRASIL, 2011). A Comissão Pedagógica Nacional cuida para que os projetos se orientem por cinco princípios fundamentais que compõe o PRONERA: a inclusão, a participação, a interatividade, a multiplicação e a parceria (ANDRADE; DI PIERRO, 2004).

A inclusão é o principio que defende a ampliação das condições de acesso à educação. O processo se dá na intenção de sanar as demandas educativas, 
sendo orientados na perspectiva de que as formas de participação, gestão e os fundamentos teórico-metodológicos dos projetos devem ampliar as condições do acesso à educação como um direito social fundamental na construção da cidadania dos camponeses (BRASIL, 2011). Objetivando a inclusão daqueles que tiveram seu direito fundante de acesso à educação negado: assentados, acampados e os sem terra. Estes sujeitos historicamente ficaram de fora ou tiveram acesso a poucos anos de vida escolar. Ainda hoje no Brasil, apesar dos dados de censos e estudos indicarem uma expansão quantitativa do acesso à escola, esse crescimento é acompanhado por desigualdades espaciais reveladas no índice elevado do número de analfabetos ou com baixa escolaridade no campo (PAIVA, 2004).

A participação é a garantia que os beneficiários e seus parceiros têm de participarem da elaboração, execução e avaliação dos projetos. A interatividade diz respeito à forma como as parcerias entre órgãos governamentais, instituições de ensino superior, movimentos sociais e sindicais e comunidades assentadas estabelecem um diálogo permanente. A multiplicação diz respeito à ampliação não só o número de alfabetizados, mas também de monitores, profissionais e agentes mobilizadores que podem dar continuidade aos processos educativos. A parceria é a condição para a realização das ações do PRONERA. São considerados parceiros do programa: as Instituições de Ensino, Pesquisa e Extensão, Públicas e Privadas sem fins lucrativos e fundações de apoio; As Secretarias Municipais e Estaduais de Educação; Os movimentos sociais e sindicais representativos do público beneficiário (BRASIL, 2011). Os projetos são implementados apenas quando ocorre a formalização do convênio entre o INCRA e a instituição de ensino proponente que deve comprovar a adesão dos movimentos sociais organizados à iniciativa (ANDRADE; DI PIERRO, 2004). As parcerias estabelecidas entre o Estado e a sociedade compreendem a uma tentativa de construção de uma democracia dos espaços públicos. A Educação do Campo no PRONERA é uma conquista dessa participação social (JESUS, 2004; CAMACHO, 2014, 2017b, 2018). 


\section{Considerações Finais}

Consideramos a inclusão como uma ação que envolve todos os educandos que vivem segregados do seu acesso à educação formal ou cerceados da garantia do direito a conteúdos e metodologias adequados a sua especificidade, sejam eles educandos do campo ou cidade, com deficiências ou sem deficiências, para que possam alcançar a autonomia e a cidadania com o direito do respeito à diversidade.

$\mathrm{O}$ acesso à educação sempre foi um direito negado para as classes subalternas no campo, por isso, o PRONERA é a oportunidade para a classe camponesa ter acesso ao conhecimento técnico - científico acumulado pela humanidade, mesmo tendo a consciência de que esta não é a única forma de conhecimento existente (CAMACHO, 2017). Os cursos do PRONERA permitem que os camponeses se apropriem do conhecimento técnico-científico para se desenvolverem pessoalmente e para auxiliarem no desenvolvimento territorial de sua comunidade. A presença dos camponeses na educação básica e superior garante que a educação formal cumpra seu papel em sua totalidade, ou seja, de formação técnica, política e social. A formação de jovens e adultos assentados e/ou acampados da reforma agrária e a capacitação de profissionais para atuarem na Assessoria Técnica, Social e Ambiental nos Assentamento de Reforma Agrária e na agricultura familiar camponesa, demonstra a efetivação de seu objetivo de construção de um desenvolvimento territorial rural inclusivo, sustentável e com respeito à diversidade sociocultural.

\section{Referências}

ANDRADE, Márcia Regina; DI PIERRO, Maria Clara ANDRADE, Márcia Regina; DI PIERRO, Maria Clara. As aprendizagens e os desafios na implementação do programa nacionais de educação na reforma agrária. In: ANDRADE, Marcia Regina; PIERRÔ, Maria Clara Di; MOLINA, Mônica Castagna; JESUS, Sonia Meire Santos Azevedo de et al. (Orgs.). A educação na Reforma Agrária em perspectiva. São Paulo: Ação Educativa; Brasília: PRONERA, 2004b. p. 37-56. 
ANDRADE, Márcia Regina; DI PIERRO, Maria Clara. A construção de uma política de educação na reforma agrária. In: ANDRADE, Marcia Regina; PIERRÔ, Maria Clara Di; MOLINA, Mônica Castagna; JESUS, Sonia Meire Santos Azevedo de et al. (Orgs.). A educação na Reforma Agrária em perspectiva. São Paulo: Ação Educativa; Brasília: PRONERA, 2004a. p. 1954.

ANTUNES-ROCHA, Maria Izabel; MARTINS, Aracy Alves. Licenciatura em Educação do campo: histórico e projeto político-pedagógico. In:

Educação do Campo: desafios para a formação de professores (Org.). Belo Horizonte: Autêntica Editora, 2009. p. 39-74. (Coleção Caminhos da Educação do Campo, 1).

ARROYO, Miguel G.; CALDART, Roseli S.; MOLINA, Mônica C. Apresentação. In: __ (Org.). Por uma educação do campo. Petrópolis: Vozes, 2004. p. 718.

BOURDIEU, Pierre. A Escola conservadora: as desigualdades frente à escola e à cultura. In: NOGUEIRA, Maria Alice; CATANI, Afrânio (Orgs). Escritos de Educação. Petrópolis: Vozes, 2008.

BRASIL, Estatuto da Pessoa com Deficiência. Brasília: Senado Federal, Coordenação de Edições Técnicas, 2015.

BRASIL. II PNERA: Relatório da II Pesquisa Nacional sobre a Educação na Reforma Agrária. Brasília: MDA, 2015.

BRASIL. Ministério do Desenvolvimento Agrário - MDA. Instituto Nacional de Colonização e Reforma Agrária - INCRA. Programa Nacional de Educação na Reforma Agrária (PRONERA). Manual de Operações do Pronera. Brasília: MDA/INCRA, 2011.

BRUNO, Marilda Moraes Garcia. A inclusão educacional de pessoas com deficiência: limites e desafios para a cultura escolar. In: KONKIEWITZ, Elisabete Castelon (Org.). Aprendizagem, comportamento e emoções na infância e adolescência: uma visão transdisciplinar. Dourados-MS: UFGD, 2013. p. 293-309.

BRUNO, Marilda Moraes Garcia. Educação infantil: saberes e práticas da inclusão. 4. ed. Brasília: MEC, Secretaria de Educação Especial, 2006.

CALDART, Roseli Salete. Educação do campo: notas para uma análise de percurso. In: MOLINA, Mônica Castagna (Org.). Educação do campo e pesquisa II: questões para reflexão. Brasília - DF: MDA/MEC, 2010. p. 103126. (Série NEAD Debate, 20). 
CAMACHO, Rodrigo Simão. O ensino da geografia e a questão agrária nas séries iniciais do ensino fundamental. 2008. 462 f. Dissertação (Mestrado em Geografia) - Universidade Federal de Mato Grosso do Sul, Aquidauana, 2008.

CAMACHO, Rodrigo Simão. Paradigmas em disputa na educação do campo. 2014. 806 p. Tese (Doutorado em Geografia) - Faculdade de Ciências e Tecnologia, Universidade Estadual Paulista, Presidente Prudente, 2014.

CAMACHO, Rodrigo Simão. Educação do campo e sustentabilidade: uma experiência

Pronera, Revista ANAP Brasil, v. 9, n. 14, 2016.

CAMACHO, Rodrigo Simão. PRONERA: considerações acerca dos dados da II PNERA In: Fórum Ambiental da Alta Paulista, 13, 2017, Tupã - SP. Anais... XIII Fórum Ambiental da Alta Paulista. Tupã: ANAP, 2017a. p. 40 - 49.

CAMACHO, Rodrigo Simão. A relação dos Movimentos Socioterritoriais Camponeses com a Universidade por meio do PRONERA: diálogos e tensionamentos. Revista Nera (UNESP), ano 20, n. 39, p.186 - 210, 2017b.

CAMACHO, Rodrigo Simão. Politicas Públicas no Campo: uma análise do Relatório da II PNERA (1998-2011) In: COELHO, Fabiano; CAMACHO, Rodrigo Simão. O Campo no Brasil Contemporâneo: do governo $\mathrm{FHC}$ aos governos Petistas (Questão Agrária e Reforma Agrária - vol. I). Curitiba: CRV, 2018. p. 297-324.

CAMACHO, Rodrigo Simão et al. Evaluation of the relationship between education and sustainability in peasant movements: the experience of the national education program in agrarian reform. Evaluation and Program Planning, v.1, p.1 - 23, 2015.

FERNANDES, Bernardo Mançano; MOLINA, Mônica Castagna. O campo da educação do campo. In: MOLINA, Mônica Castagna; JESUS, Sonia Meire Santos Azevedo de (Org.). Por uma educação do campo: contribuições para a construção de um projeto de educação do campo. Brasília: Articulação Nacional "Por Uma Educação do Campo", 2004. p. 53-91. (Por Uma Educação do Campo, 5).

JESUS, Sonia Meire Santos Azevedo de. Pronera e a construção de novas relações entre estado e sociedade. In: ANDRADE, Marcia Regina; PIERRO, Maria Clara Di; MOLINA, Mônica Castagna; JESUS, Sonia Meire Santos Azevedo de et al. (Orgs.). A educação na Reforma Agrária em perspectiva. São Paulo: Ação Educativa; Brasília: PRONERA, 2004. p. 89-100.

MANTOAN, Maria Teresa Eglér. Inclusão escolar: o que é? por quê? como fazer? São Paulo: Moderna, 2003. (Coleção cotidiano escolar). 
MENDES, Enicéia Gonçalves. A radicalização do debate sobre inclusão escolar no Brasil, Revista Brasileira de Educação, v.11, n. 33, p. 387- 559, set./dez. 2006.

MOLINA, Mônica Castagna. Politicas Públicas. In: CALDART, Roseli Salete et al. (Orgs.). Dicionário da Educação do Campo. Rio de Janeiro: Escola Politécnica de Saúde Joaquim Venâncio; São Paulo: Expressão Popular, 2012. p. 587-596.

MOLINA, Mônica Castagna. Pronera como construção prática e teórica da educação do campo. In: ANDRADE, Marcia Regina; PIERRÔ, Maria Clara Di; MOLINA, Mônica Castagna; JESUS, Sonia Meire Santos Azevedo de (Orgs.). A educação na Reforma Agrária em perspectiva. São Paulo: Ação Educativa; Brasília: PRONERA, 2004. p. 61-85.

MUNARIM, Antonio. Elementos para uma política pública de Educação do Campo. In: MOLINA, Mônica Castagna (Org.). Educação do Campo e Pesquisa: questões para reflexão. Brasília: Ministério do Desenvolvimento Agrário, 2006.

NASCIMENTO, Claudemiro Godoy do. Pedagogia da resistência cultural: um pensar a educação a partir da realidade campesina. In: ENCONTRO REGIONAL DE GEOGRAFIA, 8, 2003, Goiás. [Trabalhos apresentados], [S.L: s.n.], p. 1-11. Mimeografado.

NUNES, Clarice; MADUREIRA, Isabel Pizarro, Desenho Universal para a Aprendizagem: Construindo práticas pedagógicas inclusivas. Escola Superior de Educação do Instituto Politécnico de Lisboa, 2015. p. 1-19.

PAIVA, Irene Alves de. Escolaridade, inclusão e participação no Pronera. In: ANDRADE, Marcia Regina; PIERRÔ, Maria Clara Di; MOLINA, Mônica Castagna; JESUS, Sonia Meire Santos Azevedo de (Orgs.). A educação na Reforma Agrária em perspectiva. São Paulo: Ação Educativa; Brasília: PRONERA, 2004. p. 103-113.

PRIETO, R. G. Sobre mecanismos de (re) produção de sentidos das políticas educacionais. In: BATISTA, C. R.; CAIADO, K. R. M.; JESUS. D.M. Educação especial: diálogo e pluralidade. Porto Alegre: Mediação, 2008, p. 25-33.

SÁ, Lais Mourão; MOLINA, Mônica Castagna. Políticas de educação superior no campo. In: MOLINA, Mônica Castagna (Org.). Educação do campo e pesquisa II: questões para reflexão. Brasilia - DF: MDA/MEC, 2010. p. 7483. (Série NEAD Debate, 20).

SCHLÜNZEN, Elisa Tomoe Moriya; RINALDI, Renata Portela (Orgs.). Formação de educadores: compromisso com a educação especial na perspectiva da educação inclusiva. São Carlos SP: ABPEE: Marquezine e Manzini, 2014. 
UNESCO. Declaração de Salamanca e linha de ação sobre as necessidades educativas especiais. Brasília: UNESCO, 1994.

VIEIRA, Jaqueline Machado. Para ver os Mapas com Palavras: Audiodescrição como Recurso Pedagógico no Ensino de Geografia para a Inclusão de Pessoas com Deficiência Visual. 200 f. Dissertação (Mestrado em Educação) - Faculdade de Educação, Universidade Federal da Grande Dourados. Dourados MS, 2018. 